\title{
Pengembangan Media Pelajaran Praktik: Simulasi Sistem Proteksi Kebakaran Aktif Dengan Menggunakan Aplikasi Android
}

\author{
Wildan Nugraha, Anton Abdullah, Yacob Mandala Putra, I Gusti Ngurah Bagus Arya \\ Dwipa, Faiz Muzhaffar Nafri Gumay, Dicky Ozie Pangestian \\ Politeknik Penerbangan Palembang \\ * e-mail: wildan.nugraha@poltekbangplg.ac.id,
}

\begin{abstract}
Abstrak
Sistem proteksi kebakaran merupakan persyaratan teknis yang harus dipenuhi sebagai upaya pencegahan bahaya kebakaran pada suatu bangunan. Oleh karena itu, pendidikan dan pelatihan sistem proteksi kebakaran merupakan salah satu materi yang harus diambil dalam kurikulum di Program Studi PPKP. Penelitian ini bertujuan untuk mengatasi kendala yang dihadapi oleh maha peserta didik Program Studi PPKP dalam metode pembelajaran jarak jauh. Perlu dikembangkan media pembelajaran praktis berbasis aplikasi android untuk mengatasi kendala tersebut. Metode penelitian yang digunakan adalah metode Research and Development dengan proses pengembangan menggunakan model ADDIE (Analysis, Design, Development, Implementation dan Evaluation). Tujuan penelitian berupaya mengembangkan dan menghasilkan aplikasi media pembelajaran praktis yang valid untuk dilaksanakan berdasarkan penilaian dosen dan maha peserta didik. Penelitian ini menunjukkan bahwa hasil validasi yang dilakukan diperoleh rata-rata persentase penilaian sebesar $83,85 \%$ dengan kategori valid. Berdasarkan hasil penelitian dan pembahasan dapat disimpulkan bahwa aplikasi media pembelajaran mobile berbasis android ini valid untuk digunakan dalam pembelajaran mata kuliah Pencegahan dan Proteksi Kebakaran di Program Studi PPKP.
\end{abstract}

Keywords: Proteksi Kebakaran, Media Pembelajaran, PKP-PK.

\section{PENDAHULUAN}

Media pembelajaran merupakan metode, alat dan teknik yang digunakan sebagai media komunikasi antara seorang murid dan pengajar dalam rangka mengefektifkan komunikasi dan interaksi dalam proses pembelajaran di sekolah (Kuswanto \& Radiansah, 2018). Media pembelajaran juga dapat dipandang sebagai alat-alat elektronik atau fotografis untuk menangkap, menyusun dan memproses baik itu informasi verbal atau visual yang digunakan sebagai perangsang bagi peserta didik dalam mempelajari materi ajar di sekolah (Rosidah, 2016).

Salah satu mata kuliah yang terdapat di Program Studi Diploma Tiga Penyelamatan dan Pemadam Kebakaran Penerbangan (PPKP) Politeknik Penerbangan Palembang yaitu mata kuliah Fire Prevention and Protection, yang memiliki sub pembahasan mengenai Proteksi Kebakaran Aktif (Agung et al., 2021).

Kebakaran adalah jenis kecelakaan yang memerlukan perhatian dan pencegahan khusus (prevention) untuk mengurangi atau 
menghilangkan kemungkinan terjadinya kebakaran (Putri et al., 2019). Salah satunya dapat berupa manajemen risiko, karena sangat penting bagi perusahaan dan keberlangsungan aktivitasnya jika terjadi bencana seperti kebakaran (Kuntoro, 2019).

Pengetahuan akan sistem proteksi kebakaran baik itu pasif maupun aktif pada mata kuliah Fire Prevention and Protection sesuai degan kurikulum di bawakan oleh dosen dengan metode pembelajaran ceramah dan tanya/jawab. Media pembelajaran yang digunakan saat ini masih didominasi dalam bentuk modul konvensional atau buku (Nugraha et al., 2021).

Proses belajar mengajar tradisional sangat membosankan bagi sebagian besar siswa, karena mereka hanya mendengarkan penjelasan dosen dan menggunakan media buku teks, dan siswa kurang memperhatikan materi yang disajikan oleh dosen tersebut (Rosidah, 2016). Untuk itu perlu dikembangkan pengembangan metode pembelajaran yang terintegrasi dengan teknologi informasi agar pembelajaran yang dilakukan dapat lebih disesuaikan dan disesuaikan dengan kondisi perkembangan teknologi yang semakin cepat dan revolusi industry 4.0 (Amalia \& Nugraha, 2021).

\section{METODE PENELITIAN}

Penelitian dilaksanakan selama enam bulan di Prodi DIII PPKP Politeknik Penerbangan Palembang dan metode yang digunakan adalah jenis Research and Development (R\&D), yakni metode penelitian yang digunakan untuk membuat produk tertentu dan menguji efektivitas produk tersebut (Sugiyono, 2010).

Model R\&D yang digunakan sebagai panduan dalam penelitian ini digunakan untuk menyesuaikan model ADDIE. Tahapan pengembangan model dijelaskan dalam lima langkah/tahapan pengembangan, meliputi analisis, desain, pengembangan atau produksi, implementasi atau pengiriman, dan evaluasi. Model ADDIE dikembangkan oleh Dick and Carry pada tahun 1996 untuk merancang sistem pembelajaran (Nurhalimah et al., 2017).
Gambar 1. Tahap pengembangan media pembelajaran menggunakan model ADDIE

Instrumen yang digunakan untuk mengumpulkan data kualitas produk adalah: Pertama, Lembar angket berbentuk check list untuk mendapatkan penilaian dari ahli yang terdiri dari ahli media dan ahli materi. Aspek kriteria penilaian media pembelajaran berbasis Android untuk ahli materi adalah aspek kebahasaan, aspek kesesuaian materi dan aspek ilustrasi. Sedangkan aspek kriteria penilaian untuk ahli media adalah aspek kebahasaan, aspek grafika, aspek pengolahan program dan aspek penggunaan.

Sedangkan lembar angket berbentuk kuisioner yang digunakan untuk mendapatkan data respon peserta didik (Septiani et al., 2020). Aspek kriteria respon peserta didik yang dikumpulkan dalam penelitian ini adalah: 1) kemudahan dalam menggunakan program, 2) tampilan media pembelajaran, 3) kedalaman dan isi materi, dan terakhir 4) Kemanfaatan media. 
Tampilan skor digunakan untuk mengidentifikasi tingkat kelayakan suatu produk hasil penelitian pengembangan. Kriteria pengambilan keputusan untuk validasi media pembelajaran berbasis Android tercantum dalam tabel berikut.

Tabel 1. Persentase Kelayakan Produk (Riduwan, 2007)

\begin{tabular}{|c|c|c|}
\hline No & Persentase & Keterangan \\
\hline 1 & $80 \%-100 \%$ & Baik/Valid \\
\hline 2 & $60 \%-79,9 \%$ & $\begin{array}{c}\text { Cukup Baik/ Cukup } \\
\text { Valid }\end{array}$ \\
\hline 3 & $50 \%-59,9 \%$ & $\begin{array}{c}\text { Kurang Baik / Kurang } \\
\text { Valid }\end{array}$ \\
\hline 4 & $0 \%-49,9 \%$ & Tidak Baik (diganti) \\
\hline
\end{tabular}

\section{HASIL DAN PEMBAHASAN}

Pada analisis materi, kurikulum yang digunakan dalam pengembangan media pembelajaran Fire Prevention \& Protection adalah Kurikulum tahun 2019 yang disusun di tingkat Pusat Pengembangan Sumber Daya Manusia Perhubungan Udara (PPSDMPU) untuk Program Studi PPKP (Abdullah, 2020).

Berdasarkan silabus yang ada, dapat diidentifikasi materi pokok pada mata kuliah Fire Prevention \& Protection. Lingkup mata kuliahnya meliputi: Penjelasan bahaya kebakaran (Fire Hazard), faktor penyebab kebakaran, pecegahan bahaya kebakaran, prosedur pencegahan bahaya kebakaran, keselamatan bahaya kebakaran, sistem proteksi aktif, analisa kebutuhan sistem proteksi aktif, prosedur pengoperasian sistem proteksi aktif, sistem proteksi pasif . Pada penelitian kali ini penulis membatasi cakupan pada aplikasi yang dibuat hanya pada materi system proteksi kebakaran aktif.

Analisis yang kedua adalah terkait kepribadian peserta didik, dilakukan dalam rangka mengembangkan jenis media pembelajaran yang tepat (Amalia, 2020). Berdasarkan hasil survey peserta didik dilakukan pengumpulan data untuk menganalisis media pembelajaran proteksi kebakaran dan kebutuhan siswa akan proteksi kebakaran. Hasil wawancara menunjukkan bahwa jika materi disajikan dalam bentuk animasi dan gambar akan lebih mudah bagi siswa untuk memahami materi tersebut.
Tahap berikutnya adalah perancangan (design), bertujuan untuk merancang bentuk penyajian dari aplikasi yang akan dibuat. Perencanaan produk salah satunya adalah pembuatan flowchart media pembelajaran.

Gambar 2. flowchart media pembelajaran

Pengembangan produk dan implementasi desain mencakup beberapa kegiatan seperti pengumpulan data/materi, pemrograman, dan pengujian. Di bawah ini adalah hasil pengembangan media pembelajaran untuk latihan proteksi kebakaran (Batubara, 2017).
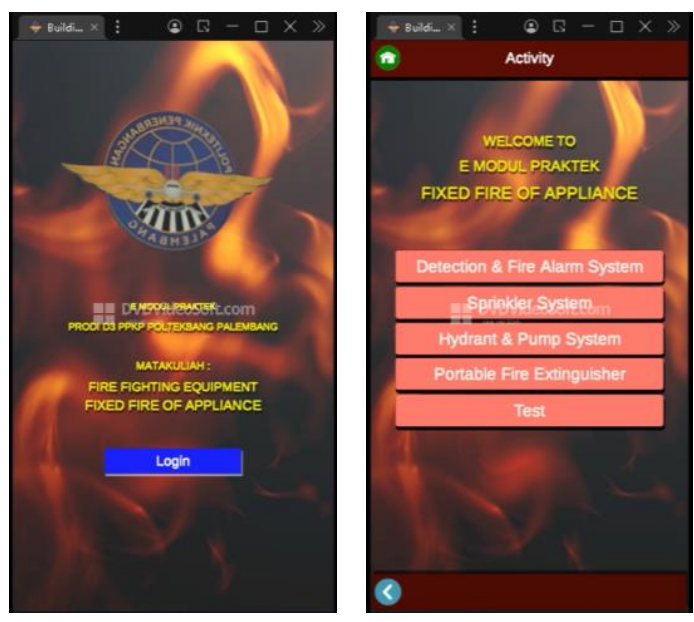

Gambar 3. Tampilan halaman utama

Halaman pembuka merupakan halaman awal pada media pembelajaran interaktif yang berisi halaman untuk masuk ke dalam aplikasi ( $\log$ in). Setelah mendaftar atau log in pengguna akan dibawa ke halaman utama yang berisi menu-menu pembelajaran baik teori 
maupun praktik, yang mana materi yang disediakan pada aplikasi ini disajikan dalam bentuk video maupun e-book. Terdapat 5 (lima) tombol menu utama yang terdiri dari masing-masing modul pembelajaran yang menjadi kompetensi inti pada materi system proteksi keabakaran aktif. Selain tombol kompetensi inti terdapat juga satu tombol "test" yang difungsikan untuk melakukan simulasi.

Warna gelap dipilih untuk latar pada halaman utama ini guna mempermudah peserta didik dalam memfokuskan perhatian pada judul media pembelajaran yang berwarna kontras dengan latar yaitu warna yang lebih cerah. Selain tulisan pada halaman pembuka diberikan animasi karakter dari logo Politeknik Penerbangan Palembang yang menyambut peserta didik saat menggunakan media pembelajaran.

Pilihan menu yang disajikan di dalam aplikasi ini telah disesuaikan dengan materi yang ada pada mata kuliah fire prevention and protection. Sub-pokok bahasan yang disajikan diantaranya adalah membahas tentang sistem deteksi dan alarm kebakaran, sprinkler system, sistem pompa dan hydrant kebakaran dan terakhir adalah terkait alat pemadam api ringan.

Halaman materi adalah halaman yang berisi materi dan video tutorial yang disediakan oleh media pembelajaran. Hal ini dimaksudkan untuk membantu siswa mempelajari materi dalam media pembelajaran (Soleh et al., 2019).

Pada halaman simulasi/test peserta didik diberi studi kasus, dimana peserta didik diminta untuk menempatkan peralatan proteksi kebakaran yang tepat dan jumlah yang sesuai untuk ditempatkan dari kompartemen dengan dimensi yang berbeda dari tiap-tiap simulasi yang dipilih. Adapun tampilan dari salah satu scenario simulasi ditampilkan pada gambar di bawah ini.
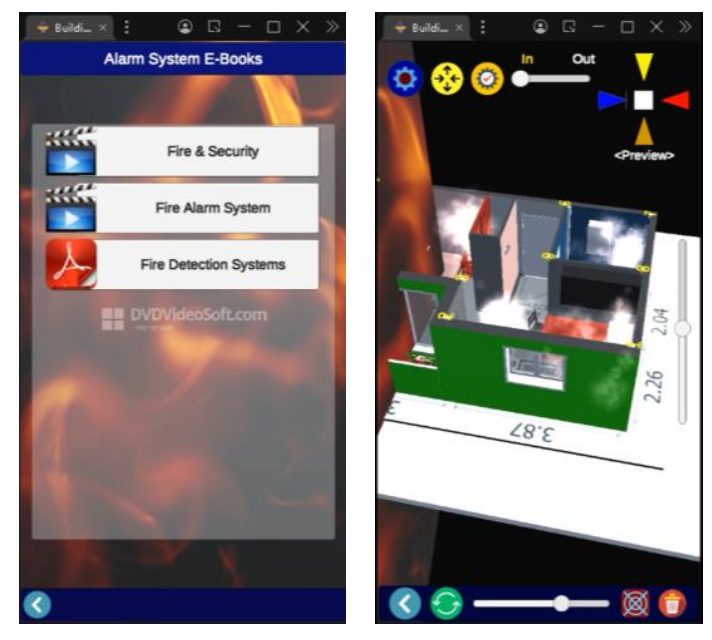

Gambar 4. Tampilan halaman simulasi

Kelayakan media pembelajaran interaktif dinilai berdasakan penilaian oleh ahli media dan ahli materi. Penilaian kelayakan media pembelajaran interaktif oleh ahli media dinilai berdasrkan empat aspek yaitu kebahasaan, grafika, pengolahan program dan penggunan. Data hasil penilaian dari ahli media dapat dilihat pada gambar berikut.

Gambar 5. Penilaian ahli media dan materi

Berdasarkan hasil analisis validasi ahli media mengenai media pembelajaran praktik system proteksi kebakaran aktif yang dikembangkan menghasilkan rata-rata persentase sebesar $83,85 \%$. Adapun saran dan masukan yang diberikan oleh ahli media adalah: "Template aplikasi sudah cukup baik, sedikit perlu penambahan akan detail grafik dari tiap-tiap konten pada aplikasi khususnya struktur kompartemen agar terlihat lebih halus lagi".

Respon penilaian peserta didik sebagai pengguna (user) terhadap media pembelajaran interaktif diperoleh dari data hasil uji coba sebagai berikut. 
Gambar 6. Evaluasi pengguna

Berdasarkan data penilaian dari 24 peserta didik (responden) sebagai pengguna maka dapat dijabarkan pada aspek pemograman sebanyak $87,5 \%$ menjawab sangat layak dan $12,5 \%$ menjawab layak, kemudian pada aspek tampilan media sebanyak 91,7\% menjawab sangat layak dan 8,3\% menjawab layak, sedangkan pada aspek isi materi sebanyak $87,5 \%$ menjawab sangat layak dan 12,5\% menjawab layak, terakhir pada aspek kemanfaatan sebanyak 95,8\% menjawab sangat layak dan 4,2\% menjawab layak.

\section{KESIMPULAN DAN SARAN}

Berdasarkan pengumpulan data validasi yang telah dilakukan oleh penilaian validator diperoleh persentase rata-rata sebesar $83,85 \%$ dengan kategori valid, maka aplikasi media pembelajaran praktik sistem proteksi kebakaran aktif berbasis android sudah valid untuk digunakan dalam pembelajaran Fire Prevention \& Protection.

Respon penilaian peserta didik terhadap media pembelajaran praktik sistem proteksi kebakaran aktif berbasis android dilihat dari aspek pemrograman (teknis), tampilan media (penyajian media), materi, dan kemanfaatan. Adapun hasil penilaian pengguna memperoleh skor $90,62 \%$ termasuk kategori "sangat layak". Adapun diharapkan aplikasi ini terus dikembangkan dan digunakan sebagai media pembelajaran berbasis digital.

\section{DAFTAR PUSTAKA}

Abdullah, A. (2020). Relationship the Work Culture and Training Programs Within Performance. International Journal of Progressive Sciences and Technologies (IJPSAT), 20(1), 92-101.

Agung, I. G., Mas, A., Abdullah, A., \& Nugraha, W. (2021). Pelatihan Dasar Pertolongan Kecelakaan Penerbangan dan Pemadam Kebakaran. 4, 222-229.

Amalia, Direstu; Nugraha, Wildan; Suryan, Viktor; Septiani, Virma; Napitulu, B. (2020). Pelatihan Basic Human Factor untuk Peningkatan Self Awareness dan Safety Culture Petugas Operasi Bandar Udara Gusti Syamsir Alam. Darmabakti: Jurnal Inovasi Pengabdian Dalam Penerbangan, 1, 9-18.

Amalia, D., \& Nugraha, W. (2021). A Study of Student Learning Attitude Towards ELearning In The Pandemic Era. 6(2), 16.

Batubara, H. H. (2017). Pengembangan Media Pembelajaran Matematika berbasis Android untuk Siswa SD/MI. MUALLIMUNA: Jurnal Madrasah Ibtidaiyah, 3(1), 12-27.

Kuntoro. (2019). 80 - Implementasi Manajemen Risiko Kebakaran Berdasarkan (Is) ISO 31000. Higeia Journal of Public Health Research and Development, 1(3), 625-634.

Kuswanto, J., \& Radiansah, F. (2018). Media Pembelajaran Berbasis Android Pada Mata Pelajaran Sistem Operasi Jaringan Kelas XI. 14(1).

Nugraha, W., Abdullah, A., Sutiyo, S., Hendra, O., \& Marwan, I. J. (2021). Basic PKPPK Initial Training Sebagai Sarana Peningkatan Pelayanan Gawat Darurat di Bandar Udara. Darmabakti: Jurnal Inovasi Pengabdian Dalam Penerbangan, 1(2), 121-130. https://doi.org/10.52989/darmabakti.v1i2. 25

Nurhalimah, S. R., Suhartono, S., \& Cahyana, U. (2017). Pengembangan Media Pembelajaran Mobile Learning Berbasis Android pada Materi Sifat Koligatif Larutan. JRPK: Jurnal Riset Pendidikan Kimia, $\quad 7(2), \quad 160-167$. https://doi.org/10.21009/jrpk.072.10 
Wildan Nugraha, Anton Abdullah, Yacob Mandala Putra, I Gusti Ngurah Bagus Arya Dwipa, Faiz Muzhaffar Nafri Gumay, Dicky Ozie Pangestian

Pengembangan Media Pelajaran Praktik: Simulasi Sistem Proteksi Kebakaran Aktif Dengan Menggunakan Aplikasi Android

Putri, N. A., Martono, Mawardi, Setyono, K. J., \& Sukoyo. (2019). Analisis Sistem Proteksi Kebakaran Sebagai Upaya Pencegahan Kebakaran. Bangun Rekaprima, 05(2), 59-69.

Riduwan. (2007). Skala pengukuran variabelvariabel penelitian. Alf. Bandung.

Rosidah, A. (2016). Kata Kunci: Hasil Belajar, IPS, Media Pembelajaran Visual 121. 2, 122.

Septiani, V., Amalia, D., \& Cahyono, D. (2020). Implementation of Inspector Training System Certification Learning Based On E-Learning in Palembang Aviation Polytechnic. International Journal of Progressive ..., 342-346. http://www.ijpsat.es/index.php/ijpsat/artic le/view/2271

Soleh, A. M., Tobari, \& Kesumawati, N. (2019). Development of the practical manual as a learning media for simulator aircraft rescue and fire fighting. International Journal of Scientific and Technology Research, 8(10), 523-526.

Sugiyono. (2010). Metode penelitian kuantitatif dan kualitatif dan $R \& D$. Alfabeta Bandung. 